Thorax (1963), 18, 59

\title{
A clinico-pathological study of emphysema in an American hospital
}

\author{
W. M . TH U R L B E CK \\ From the Department of Pathology, Pathological Institute, McGill University, Montreal, Canada
}

In 1951 Monroe found that the clinical and the pathological diagnoses of emphysema agreed in less than $5 \%$ of patients. His study, performed at a leading American hospital, is a convenient reference point since it antedates the widespread use of diagnostic pulmonary function tests as well as the recent advances in the morbid anatomy and methodology used for the pathological diagnosis of emphysema. It might be anticipated that a much better correlation could be achieved to-day, and the first part of this paper will show that this is the case. This study also provided an opportunity to investigate the relationship between emphysema, as a disorder of anatomy, and various conditions such as chronic bronchitis, fibrocystic disease of the pancreas, and peptic ulcer. This was particularly interesting since the relationship of these conditions to emphysema had previously been derived from the diagnosis of emphysema by clinical means, by inadequate pathological data, or by simple tests of pulmonary function. To some extent this study reflects a difference in attitude toward chronic lung disease between workers in the United States and in the United Kingdom, and this may be of particular interest to the British reader.

\section{MATERIALS AND METHODS}

One hundred and fifty-nine cases from the necropsy service of the Massachusetts General Hospital were studied. One hundred and thirtyeight were adult patients who had died in preselected weekly periods and were representative of the necropsy population. The remaining 21 were examples of severe emphysema encountered at times other than the preselected periods. Lungs from the 138 random cases and from 18 of the 21 cases of severe emphysema were distended by positive pressure with intrabronchial formalin until they were considered to be fully expanded. The bronchus was then clamped and the lungs were left overnight in a large tank of formalin. Subsequent experiments have shown that the volume of lungs prepared in this way is $23 \cdot 2 \pm$ $10 \%$ less than their volume at maximum inflation produced by a constant intrabronchial pressure of $43 \mathrm{~cm}$. of formalin for 12 to 14 hours. Lungs from two cases of severe emphysema were inflated at a constant pressure of $12 \mathrm{~cm}$. of formalin. Lungs from five cases of severe emphysema were fixed and air-dried with formalin gas and alcohol vapour at a constant pressure of $12 \mathrm{~cm}$. of water for seven days. In four of the latter group the other lung was distended by intrabronchial formalin to apparently full inflation.

All lungs were cut into sagittal slices 1 to $1.5 \mathrm{~cm}$. thick and examined with a dissecting microscope. The slices from fluid-fixed lungs were impregnated with barium sulphate and studied under water (Heard, 1958). The lungs from the 138 random cases and from about half of the cases of severe emphysema were examined without knowledge of the patient's age, sex, clinical history, or necropsy diagnosis. The presence and severity of emphysema were assessed in each of 10 zones, which corresponded approximately to the classical segments of the right lung. These were anterior, posterior, and apical zones in the upper lobe; superior, anterior, posterior, medial, and lateral zones in the lower lobe ; and superior and inferior zones in the middle lobe or lingula. This system was used irrespective of side, but, when both lungs were available, the right was used.

Representative abnormal and normal areas were photographed in all cases, usually through the dissecting microscope, and the corresponding areas taken for histological study. Serial section reconstructions were made where considered appropriate, and runs of 25 to 50 sections were frequently cut to establish the nature of particular structures. After examination of photographs and sections, a final grading of severity and decision as to type were made.

The average severity of emphysema in each of the 10 zones was graded 0 to 3 , i.e., absent, mild, moderate, and severe, giving, by addition, a possible maximum of 30 units of emphysema for 
each lung. The methodology used precluded recognition of emphysema due to dilatation alone, i.e., where the lung structure was intact but the spaces were just slightly larger than normal. Hence only destructive forms of emphysema were recognized. Thus, grade 1 mild panacinar emphysema corresponded to the Ciba Guest Symposium (1959) moderate grade, and a new moderate grade was introduced (Fig. 1). The Ciba Symposium grading

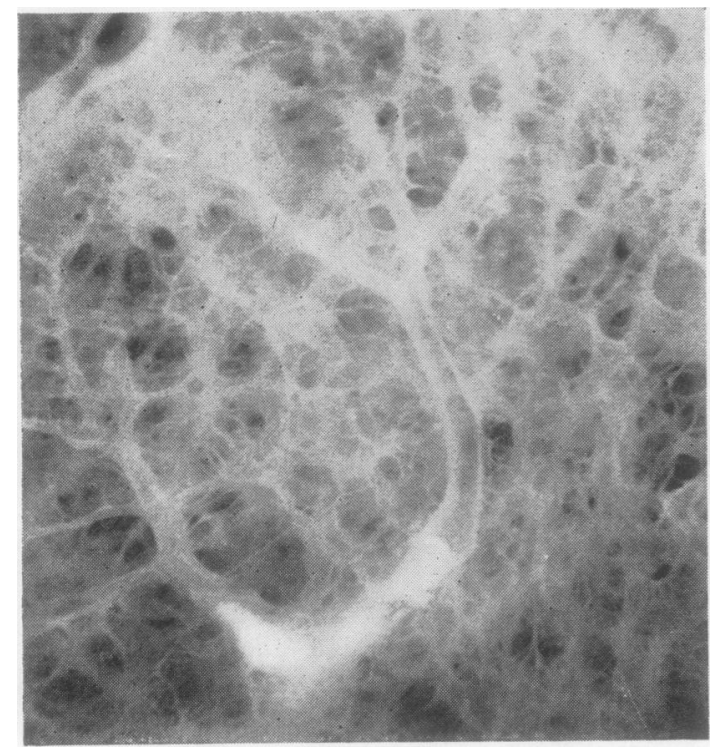

FIG. 1. Typical moderate grade of panacinar emphysema. Slice of lung impregnated with barium sulphate and photographed under water. A branch of the pulmonary artery contains a barium-gelatin injection mass. $\times 9$.

for centrilobular and severe panacinar emphysema was used. It was found possible to recognize alveolar duct emphysema (Heppleston and Leopold, 1961), all examples of which were considered mild or grade 1. This form of emphysema is regarded as a variant, probably an early stage, of panacinar emphysema. These two forms of emphysema were frequently encountered in the same lung, or within the same areas of the same lung, and at times they merged imperceptibly into each other.

Irregular emphysema was ignored in the final grade since it was present in most cases, and no evidence was found that it was functionally significant when present alone. Paraseptal emphysema was occasionally observed, but was disregarded in the grading system since it was invariably associated with other forms of emphysema which overshadowed it. Where two types of emphysema were present in the same zone, the higher grade was used, thus the value never exceeded 3 units per zone. Regrading of 15 lungs showed good reproducibility $(r=0.98)$.

The detailed anatomical pathology of these cases is described elsewhere. About half of the random cases showed emphysema which could be classed as centrilobular, panacinar, or alveolar duct types.

The cases were then divided into four groups: Group 1, no emphysema (0 unit); group 2, mild emphysema (1 to 5 units); group 3 , moderate emphysema (6 to 15 units); and group 4, severe emphysema (16 or more units).

When the groups were analysed, it was found that the average age and proportion of men in group 4 were higher than in any of the other groups or in the series as a whole. Accordingly, a group of the same age and sex, but with little or no emphysema, was selected from the 138 random cases to be compared with group 4 . The control group consisted of all the men aged 50 years or older with no emphysema (17 cases), 11 men aged 50 years or older with 3 units or less of emphysema, and two women aged over 70 years without emphysema.

CRITERIA USED The following criteria were used to place patients in each of the various clinical and pathological categories.

Clinical diagnosis of emphysema The sole criterion used was that the diagnosis had been recorded as such in the patient's chart and that the patient was able to give an adequate history. Seven patients with no emphysema, seven patients with mild emphysema, one patient with moderate emphysema, and four patients with severe emphysema were excluded because they were unconscious or dying on admission, and no adequate history was available. When emphysema was recorded by one observer but not by another, as happened on three occasions, the opinion of the senior observer was accepted.

Radiological diagnosis of emphysema The radiological diagnosis was considered to have been made when recorded as such on the radiograph report or when the diaphragms were described as low and flat and the lung fields as hypertranslucent. Cases without chest films were excluded.

Diagnosis of emphysema on death certificate At the Massachusetts General Hospital death certificates are filled in by the pathologist after he has completed the necropsy, and a facsimile is kept in the patient's chart. Three items are recorded on the death certificate, the 'immediate cause of death', the 'underlying cause of death', 
and 'other significant conditions present'. If only the immediate cause of death is recorded, this is used for computing statistics. More commonly, both immediate and underlying causes of death are recorded, and then the latter is used for statistics, e.g., if the immediate cause of death is recorded as $(a)$ cor pulmonale, due to $(b)$ chronic bronchitis, due to $(c)$ mucoviscidosis, it is $(c)$, the underlying cause, that is used for statistical purposes (McNeil, 1961).

The facsimiles of death certificates were examined and the cases divided into three groups, those in which emphysema would appear in standard mortality statistics, those in which emphysema was recorded as a significant condition present but not causing death, and those in which no mention was made of emphysema.

The facsimile of the death certificate of one patient, who died of severe emphysema, could not be found and this case was omitted.

Chronic bronchitis A patient was considered to have chronic bronchitis when a productive cough, or cough with sputum, described as chronic or of two or more years' duration, was recorded in the chart. No examples of sputum without cough were recorded. Patients having the following symptoms were not regarded as cases of chronic bronchitis : coughs described as dry, non-productive, or with blood; coughs without specification as to the presence or absence of sputum ; productive coughs of less than two years' duration; and no cough. One patient with heart failure due to rheumatic heart disease complained of a productive cough 'when congested'. This was not considered an example of chronic bronchitis. When no statement was made about cough, the case was excluded, even if such terms as 'review of respiratory systems negative' were used.

Smoking When no smoking history was recorded, the case was discarded. The remaining patients were divided into non-smokers and smokers, and the latter subdivided into five categories: 1 Patients who smoked less than 10 cigarettes per day, or who were called light, mild, or occasional smokers; 2 those who smoked 10 to 19 cigarettes per day or who were termed moderate smokers; 3 those who smoked 20 or more cigarettes per day or were called heavy smokers; 4 ex-smokers; and 5 pipe and cigar smokers.

Chest infections other than bronchitis Any patient who admitted to a past history of pneumonia or tuberculosis was placed in this category. Unless these chest illnesses were specifically denied, the cases were omitted.
Asthma Patients were considered to have asthma when this diagnosis or a diagnosis of asthmatic bronchitis, as happened twice, was recorded. Unless asthma was specifically denied in the remaining cases they were discarded. A description of wheezing or attacks of wheezing was not accepted unless the diagnosis of asthma was also made.

Non-neoplastic abnormalities of the pancreas Patients with the following gross abnormalities recorded at necropsy were included in this category: fatty replacement of the pancreas, chronic pancreatitis, calcification of the pancreas, and atrophy of the pancreas. The histological sections of the pancreas were examined separately and the above abnormalities, as well as squamous metaplasia of the ducts, dilatation of the ducts, and the presence of inspissated secretion, were tabulated separately.

Chronic peptic ulceration, past and present Patients in whom chronic or healed gastric or duodenal ulcers were found at necropsy, or patients who had had gastric surgery for ulcer were placed in this category. One patient, in whom a gastric ulcer had been seen gastroscopically several years previously, was included. All other patients were regarded as not having chronic peptic ulcer.

Cor pulmonale Patients were considered to have cor pulmonale when this diagnosis was made on the final necropsy report, or when the right ventricle was more than $5 \mathrm{~mm}$. thick and the right ventricular muscle was described as hypertrophied. Cases were excluded as examples of cor pulmonale if pulmonary causes, other than emphysema, or cardiac causes of right ventricular hypertrophy were found at necropsy.

Arteriosclerotic aneurysm of the aorta Those cases in which an arteriosclerotic aneurysm of the descending thoracic or abdominal aorta was found at necropsy were included.

\section{RESULTS}

The size, age, and sex characteristics of groups 1 to 4 and the control group are presented in Table I.

Figure 2 shows the percentage of cases in groups 1 to 4 in which the diagnosis of emphysema was made clinically, radiologically, or on the death certificate.

Each diagram in Fig. 3 shows the incidence of a particular condition in groups 1 to 4 expressed as a percentage of each group. The probability factor (P) of the irregularity of distribution 

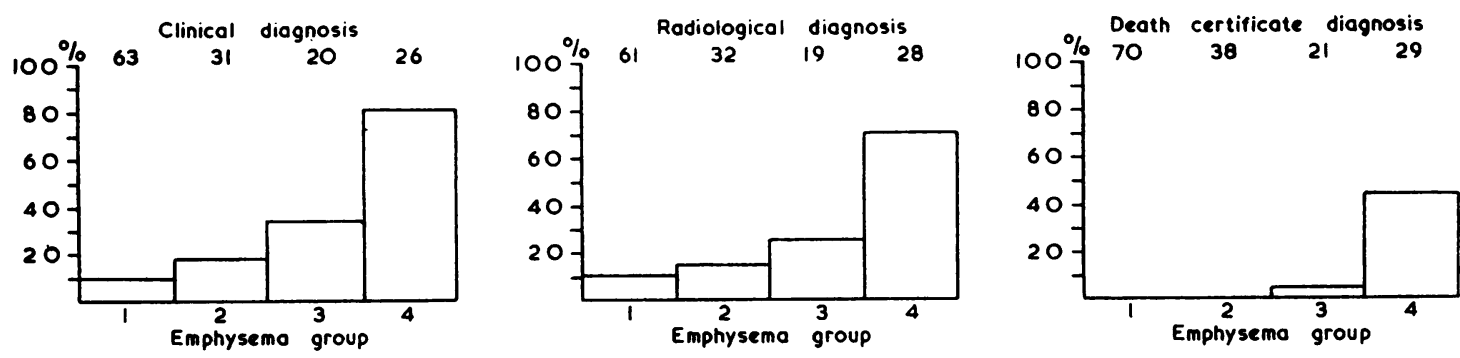

FIG. 2. The clinical, radiological, and death certificate diagnosis of emphysema in each of the four groups. The number of cases in each group is given at the top of the diagrams above each column.

Chronic Bronchitis $(p<0.01)$
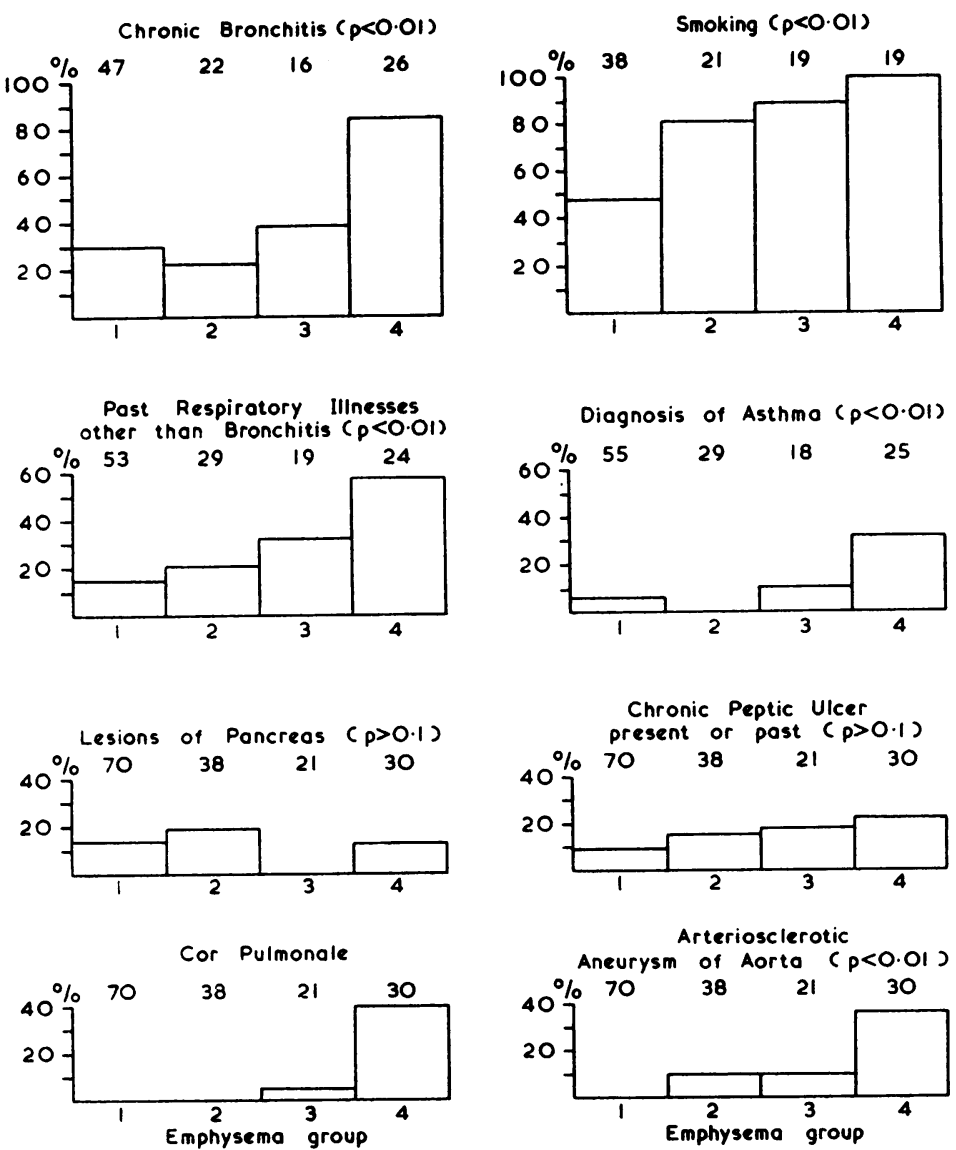

FIG. 3. The relationship between eight conditions and the amount of destructive emphysema present. The number of cases in each group is given at the top of each diagram above the appropriate column. The incidence of each condition in the 138 random patients is as follows : Chronic bronchitis, 34\%; smoking, $70 \%$; past respiratory illnesses other than bronchitis, $22 \%$; diagnosis of asthma, $5.5 \%$; lesions of pancreas, $13 \%$; chronic peptic ulcer, past or present, $13 \%$; arteriosclerotic aneurysm of aorta, $7 \cdot 3 \%$. 
TABLE I

SEX AND AVERAGE AGE IN THE FOUR GROUPS

\begin{tabular}{lcccc} 
& $\begin{array}{l}\text { Total } \\
\text { Number }\end{array}$ & Male & Female & $\begin{array}{l}\text { Average } \\
\text { Age } \\
\text { (Years) }\end{array}$ \\
\hline $\begin{array}{l}\text { Group 1, no emphysema } \\
\begin{array}{l}\text { Group 2, mild emphysema } \\
\text { (1-5 units) }\end{array}\end{array}$ & 70 & 25 & 45 & 63.2 \\
$\begin{array}{l}\text { Group 3, moderate } \\
\text { emphysema }\end{array}$ & 38 & 28 & 10 & 63.6 \\
$\begin{array}{l}\text { Group 4, severe } \\
\text { emphysema }\end{array}$ & 21 & 18 & 3 & 65.8 \\
$\begin{array}{l}\text { Control group, no or } \\
\text { minimal emphysema }\end{array}$ & 30 & 28 & 2 & 70.7 \\
& 30 & 28 & 2 & 70.2
\end{tabular}

TABLE II

INCIDENCE OF CONDITIONS IN THE CONTROL GROUP

\begin{tabular}{lcc} 
& $\begin{array}{l}\text { No. of } \\
\text { Cases with } \\
\text { Sufficient } \text { Data }\end{array}$ & $\begin{array}{l}\text { Incidence } \\
(\%)\end{array}$ \\
\hline Chronic bronchitis & 20 & 20 \\
Smoking & 20 & 65 \\
Respiratory illness & 25 & 16 \\
Diagnosis of asthma & 25 & 12 \\
Lesions of pancreas & 30 & 30 \\
Chronic peptic ulcer & 30 & 27 \\
Aneurysm of aorta & 30 & 6.7
\end{tabular}

between the four groups for each particular condition is derived from calculation of the chi-square. For example, $\mathrm{P}<0.01$ for 'chronic bronchitis' indicates that the chances are less than 1 in 100 that the uneven distribution of chronic bronchitis observed between the four groups arose by chance.

Table II summarizes the findings in the control group. It should be noted that the incidence of smoking, respiratory illness, asthma, abnormalities of the pancreas, and aneurysm was within one standard error of the difference between their proportions in the control group and in the 138 random cases, and the incidence of bronchitis and ulcer was within two standard errors.

\section{DISCUSSION}

CLINICAL DIAGNOSIS OF EMPHYSEMA The clinical diagnosis of emphysema was made correctly in 21 of the 26 patients $(81 \%)$ with severe emphysema. This could not be ascribed solely to the use of pulmonary function tests since these were performed in only nine of the patients, and in six of these only the timed vital capacity was determined. The mean indirect maximal breathing capacity in the nine patients was $22 \pm 7 \cdot 6$ (13 to 39) litres per minute. In all the patients correctly diagnosed, the emphysema was symptomatic, and in 17 it was the major cause of death, generally complicated by pneumonia. The remaining four patients had other serious disease and presented complicated clinico-pathological problems; three of these have been described in detail elsewhere (Case Records of the Massachusetts General
Hospital, 1960a, b; 1961). The five patients with severe emphysema, in whom the clinical diagnosis was not made, had other major disease. Three patients had advanced cancer and two had a ruptured aneurysm of the abdominal aorta ; death was not due to emphysema in these cases.

Analysis of the six patients without anatomic emphysema, who were diagnosed as having emphysema, showed that the clinical diagnosis was a secondary one in patients with other major disease. Three also had long-standing chronic bronchitis, and two of these were diagnosed as having asthma.

The accuracy of the clinical diagnosis of emphysema appears to be reasonably satisfactory and compares favourably, for example, with that of carcinoma of the lung or of acute appendicitis before tissue confirmation. It seems unlikely that the much better correlation noted in this series, as compared to Monroe's (1951), is due solely to improved clinical diagnosis, since most of the patients presented a classical clinical picture. It is therefore probable that the pathological diagnosis in his series was often incorrect. The distribution of the clinical diagnosis within the four groups provides evidence that there is good correlation between altered anatomy and symptoms, which Monroe doubted. Patients with severe anatomic emphysema invariably showed symptoms of this, provided the symptoms were not overshadowed by other serious illnesses. The relationship between the clinical and anatomical state is not constant, however, since one of the patients with mild emphysema and four patients with moderate emphysema were considered clinically to have emphysema as their major disease. The four latter patients had 11 to 15 units of emphysema, i.e., they were in the upper range of the moderate group, and one had cor pulmonale. The one patient with mild emphysema had a long-standing history of chronic bronchitis and repeated pulmonary infections. When admitted to hospital for the last time, the arterial oxygen saturation was $80 \%$ and the $\mathrm{PCO}_{2} 74 \mathrm{~mm}$. $\mathrm{Hg}$. At necropsy, he was found to have severe coronary heart disease with old and new myocardial infarcts, plugging of the bronchi with mucopurulent secretion, and focal bronchopneumonia. There was only mild centrilobular emphysema involving the upper lobe and apical segment of the lower lobe. This was the best example encountered in this series of 'clinical emphysema without anatomical emphysema', alluded to by Baldwin, Cournand, and Richards (1949) and by Cromie (1961), but it was felt that the symptoms could 
be explained on the basis of bronchitis, coronary heart disease, and terminal infection.

RADIOLOGICAL DIAGNOSIS OF EMPHYSEMA The radiological diagnosis of emphysema was made by several radiologists, exercising no more than their usual care, and no attempt was made to re-interpret the radiographs in the light of the pathological diagnosis. The correct diagnosis in $71 \%$ of the patients with severe emphysema is gratifying in view of the criticism made of the radiological diagnosis in patients considered to have emphysema on the basis of pulmonary function tests (Knott and Christie, 1951 ; Whitfield, Smith, Richards, Waterhouse, and Arnott, 1951; Fraser and Bates, 1959). The accuracy of the diagnosis reported here, though not as good, compares favourably with that obtained by tomography by Fraser and Bates. The radiological diagnosis of emphysema in patients with normal lungs was made six times. The clinical diagnosis was not made in five of these patients, and emphysema was considered to be present clinically in the sixth.

DEATH CERTIFICATE DIAGNOSIS OF EMPHYSEMA Emphysema was recorded by the pathologist as the cause, or the underlying cause, of death in 13 of the 29 patients with severe emphysema, and in one of the patients with moderate emphysema, and it would thus appear in public health statistics. In a further seven cases of severe emphysema and two of moderate emphysema, emphysema was recorded under 'other significant conditions' on the death certificate. Where the cause, or the antecedent cause, of death was not thought to be emphysema, death was ascribed by the pathologist to the other major disease process present, or to pneumonia. Since death certificates were filled in by pathologists in this series, they are likely to be more accurate than most. The incidence of emphysema, as recorded by them, was an underestimate of the incidence of severe emphysema, and lesser grades of emphysema were ignored.

It has been pointed opt that the major difference in mortality statistics for chronic lung disease between the United Kingdom and the United States is the 45 times greater mortality ascribed to chronic bronchitis in the United Kingdom (Fletcher, 1959). This was illustrated in this series by the fact that chronic bronchitis was considered as the cause of death only once, and it was never recorded under 'other significant conditions'.

CHRONIC BRONCHITIS The association between chronic bronchitis and emphysema is a long and honourable one. It was described by Laennec $\bar{C}$ (1838), who thought that emphysema resulted from bronchitis. Andral, annotating Laennec's book, and other authors (Louis, 1838 ; Waters, 1862) in the early nineteenth century had a contrary is opinion, and this problem has still not been resolved. The customary practice in Britain seems to be to couple the two conditions, and who knows what else, under the heading of 'chronic bronchitis', while in the United States they are recorded as emphysema. An analysis of the relationship between the two conditions is difficult. Using simple tests of pulmonary function to do this is to some extent self-defeating because chronic bronchitis without emphysema can cause increased airway resistance (Bates, Woolf, and Paul, 1962). Thus, using tests which measure increased airway resistance directly or indirectly as a criterion for emphysema leads to a meaningless result. If both conditions can cause the same functional result, and only one is defined in terms of this disturbance of function, then obviously the two will be closely related. A study has been reported by Gaensler and Lindgren (1959) from Boston, which shows that chronic bronchitis was present in $86 \%$ of patients with emphysema, as $\stackrel{\mathbb{D}}{\triangle}$ defined by abnormalities of maximal breathing capacity with little improvement after the use of bronchodilators, air velocity index, timed vital capacity, residual volume, and nitrogen washout. In $68 \%$ of their cases, bronchitis preceded the onset of dyspnoea, and in $18 \%$ it appeared subsequently. It is not clear how much bronchitis per se $\underset{x}{\times}$ contributed to the disturbances of function in $\frac{\sigma}{3}$ Gaensler's cases, but the $85 \%$ incidence of bronchitis found in this series is remarkably similar to his. It was not possible to determine accurately from the patients' records whether 을 bronchitis or dyspnoea appeared first in this series. Four patients with severe emphysema denied 을 habitual sputum, and two of these also denied $\stackrel{\sim}{\mathrm{N}}$ cough. However, all four patients showed mucous $\Omega$ gland hypertrophy by the method of Reid (1960). N It seems that even in Boston chronic bronchitis is a very frequent accompaniment of severe pulmonary emphysema, as assessed pathologically as 0 well as by the usual clinical or functional methods. The incidence of chronic bronchitis in patients $\stackrel{?}{?}$ with lesser degrees of emphysema differed little 0 from that in patients without emphysema. In 0 part, retrospective analysis of clinical records may $\mathbb{D}$ account for this, since there are inherent deficien- $\mathbb{\mathbb { D }}$ cies in this technique. A current study of the $\frac{\Omega}{\sigma}$ relationship between emphysema and chronic bronchitis, using the Reid index, will be reported 
elsewhere. Two facts, however, emerged from the above cases. First, patients could have a long history of chronic bronchitis, indistinguishable from that of patients with emphysema, and yet have little or no emphysema at necropsy. Secondly, minor degrees of emphysema could be present at necropsy although a completely negative history of chronic bronchitis had been reported on several occasions.

A curious anomaly was noted in the control group. This group, though consisting almost entirely of men, had a lower incidence of chronic bronchitis than the 138 representative random cases. Although this is surprising, the incidence is within two standard errors and may thus have arisen by chance.

SMOKING Lowell (Lowell, Franklin, Michelson, and Schiller, 1956a, b ; Franklin and Lowell, 1961), in particular, has stressed the relationship between smoking and emphysema. However, in a series of patients diagnosed as having emphysema on the basis of airway obstruction, hyperinflation of the lungs, and impaired mixing, Gaensler and Lindgren (1959) found that only $69 \%$ were smokers. In view of the well-known association between bronchitis and smoking (Oswald, Harold, and Martin, 1953 ; Palmer, 1954 ; Oswald and Medvei, 1955 ; Leese, 1956), it is possible to postulate that the expiratory airflow obstruction observed by Lowell and his associates, and regarded by them as evidence of emphysema, was due to bronchitis rather than to emphysema. However, a striking relationship was found between smoking and emphysema in this series. No patient with severe emphysema, and only two patients with moderate emphysema, denied smoking. These two patients, one a barman and the other an ex-chorus girl, both died from cirrhosis of the liver and denied drinking as well as smoking. In addition, the patients with severe emphysema were heavier cigarette smokers than those without. The high incidence of smokers among the patients with severe emphysema cannot be explained on grounds of the difference in age and sex, since the control groups, with the same age and sex distribution, had smoking habits similar to those of the 138 random patients.

PULMONARY INFECTIONS A history of past chest infections other than bronchitis was analysed because a number of patients with severe emphysema dated the onset of dyspnoea from the time of a pulmonary infection. The difference between the groups is significant, but no interpretation could be made from the data because the nature of the previous illnesses could rarely be substantiated from previous admission records. It is conceivable that many of these episodes were attacks of acute bronchitis, diagnosed by the patient or his physician as pneumonia.

ASTHMA The diagnosis of asthma was made more frequently in the patients with severe emphysema. Whether or not this is 'true asthma' is questionable, but at a significant statistical level this group more frequently had spasmodic attacks of wheezing and dyspnoea, usually associated with pulmonary infections. The onset in all occurred in middle life. The patients in the other groups, with asthma and little or no emphysema, were similar clinically, except that they did not die with or of respiratory failure. No case of juvenile asthma was included, and no patient died of status asthmaticus. The above analysis does not contradict Gough's observation (1955) that patients with a long history of extrinsic asthma do not have emphysema, nor is it suggested that asthma was the cause of emphysema. It merely states that patients who have severe emphysema more frequently have asthma, as diagnosed in Boston, although many British observers would call this bronchitis. It does stress the importance of distinguishing between middle-aged men with asthma and severe emphysema and those with little or no emphysema, since the former died of chronic lung disease whereas the others did not. This is clearly a difficult distinction to make, but it can be done by tomography (Fraser and Bates, 1959) or by measurement of the diffusing capacity (Bates, 1958).

ABNORMALITIES OF THE PANCREAS It is well known that chronic lung disease is a feature of fibrocystic disease of the pancreas, and Wood, Fishman, Reemtsma, Barker, and di Sant' Agnese (1959) found that five of 24 patients with emphysema, diagnosed by tests of pulmonary function, had abnormally high sweat chloride concentrations. Four of the five also had impaired intestinal absorption of neutral fat. Wood et al. concluded that some cases of emphysema might be formes frustes of fibrocystic disease. It is therefore of interest to note that two of the 30 patients with severe emphysema in this series had marked pancreatic fibrosis and acinar atrophy. No indication was given in their records that they or their relatives suffered from mucoviscidosis. Marked bronchiectasis, excessive tenacious mucopurulent secretion, and extensive pulmonary fibrosis have 
been described in adult cases of mucoviscidosis (Polgar and Denton, 1962). The two patients in this series did not show these features, and the emphysema was in no way different from that of the others. It is therefore unlikely that they represented adult cases of mucoviscidosis. Further, statistical analysis of the gross and microscopical abnormalities of the pancreas showed no difference between the groups with varying degrees of emphysema. However, the association between emphysema and overt fibrocystic disease is likely to be rare and might not be apparent in a small series. Statistical deductions concerning emphysema as a forme fruste of fibrocystic disease would be of more value, since this relationship, if it exists, should be more common and might influence the analysis. There is no difference in visible pancreatic abnormalities between the groups; therefore, if emphysema is sometimes a forme fruste of fibrocystic disease of the pancreas, this manifestation occurs without significantly more frequent pancreatic abnormalities. This does not exclude the possibility of a relationship, since the patients with abnormal sweat chlorides and impaired fat absorption, described by Wood et al., had normal pancreatic trypsin. Morphological abnormalities of the pancreas may not be part of the forme fruste, and the relationship to emphysema must still be judged on the basis of physiological and biochemical data.

CHRONIC PEPTIC ULCER Many studies have shown that the incidence of peptic ulcer in patients with emphysema is high (Cohen and Jenney, 1962; Flint and Warrack, 1958; Fulton, 1953; Green and Dundee, 1952; Latts, Cummins, and Zieve, 1956 ; Lowell et al., 1956a ; Plotkin, 1957 ; Silen, Brown, and Eiseman, 1959 ; Zasly, Baum, and Rumball, 1960). The diagnosis of emphysema has been made on clinical and pathological data, and the incidence has generally been two to three times that expected. Figure 3 shows that the high incidence of peptic ulceration in patients with severe emphysema has been confirmed. Seven $(23 \%)$ of the patients with severe emphysema had chronic peptic ulcer, three of them antedating the symptoms of emphysema. There is also a stepwise increase in the incidence of chronic peptic ulcer with increasing severity of emphysema in the groups, but statistical analysis shows that this difference is not significant $(P>0 \cdot 10)$. The incidence of chronic peptic ulcer in the control group, of the same age and sex, is about the same as that in the patients with severe emphysema. Therefore, in this series, the increased incidence of ulcer in patients with severe emphysema iso linked to age and sex and is, in any event, noto statistically significant.

Adequate control groups were not used in theo reports mentioned above, but Cohen and Jenney (1962) reported that the incidence of peptic ulcers in patients dying of pulmonary tuberculosis was. almost identical with that in patients dying of emphysema. Although the tuberculosis group was not designed as a control, the age and sex distribu-F tion was similar. The raised incidence of peptic. ulcer in both groups supports the above contention $\infty$ that this increase may be due to a large extent to $\overrightarrow{\vec{r}}$ age and sex selections within the groups. It should 0 also be noted that Flint and Warrack (1958) and? Fulton (1953) found an increased incidence of acute peptic ulcer but not of chronic ulcer.

COR PULMONALE Cor pulmonale was found in $12^{\Im}$ $(40 \%)$ of the patients with severe emphysema and $\%$ in one $(5 \%)$ of the patients with moderate emphy- $\omega$ sema. This patient had 11 units of emphysema, i.e.,잉 he was one of the more severely affected patients in the moderate emphysema group. These observa- $\frac{}{0}$ tions are in agreement with those of Sweet, Wyatt, Fritsch, and Kinsella (1961), who found a good $\mathbb{Q}$ correlation between the severity of emphysema $\overrightarrow{7}$ and cor pulmonale, but not with those of Cromie 3 (1961), who found no correlation. Our series wastoo small, and the type of emphysema was so frequently mixed that the difference of opinion between Sweet et al. (1961), who maintain thato cor pulmonale is more common in panacinar emphysema, and Leopold and Gough (1957), who:found it to be more common with centrilobular 3 . emphysema, could not be evaluated. Cor pulmonale was found more commonly in patients with clinical evidence of right heart failure, buto the relationship between emphysema, right heart? failure, and cor pulmonale is complex, sinceo patients with apparently identical lungs differed $\underset{N}{\bar{N}}$ in clinical presentation and degree of right hearto hypertrophy.

ARTERIOSCLEROTIC ANEURYSM Thirty-seven per cent of patients with severe emphysema hade arteriosclerotic aneurysms of the aorta. This

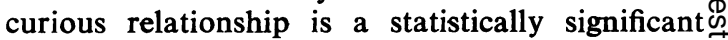
one and is not due to age and sex linkage. $A_{T}$ further control group of 420 men and 40 womeno over the age of 50 was also studied, and the $\overrightarrow{\mathbb{\otimes}}$ incidence of arteriosclerotic aneurysm of the $\frac{?}{\mathbb{D}}$ descending thoracic and abdominal aorta was $\varrho$ found to be $9 \cdot 3 \%$. The age and sex distribution of this group was similar to that of the patients witho 
severe emphysema, and the relationship between aneurysm and emphysema was confirmed.

The incidence of aneurysms in emphysema was analysed because this association was noted in four consecutive patients with severe emphysema, and in three the aneurysm had ruptured. Thus the relationship may have been brought about by this fortuitous recognition of a small group of cases. Further studies are being pursued in Montreal which should settle this question.

\section{SUMMARY AND CONCLUSIONS}

The lungs from 138 random necropsies performed at the Massachusetts General Hospital in preselected weekly periods and from 21 cases with severe emphysema were examined in a standard way. The 159 cases were divided into four categories based on the extent and severity of destructive emphysema. The four groups consisted of patients with no emphysema, mild emphysema, moderate emphysema, and severe emphysema.

The incidence of the following was analysed in each of the four groups: clinical diagnosis of emphysema, radiological diagnosis of emphysema, death certificate diagnosis of emphysema, chronic bronchitis, smoking, chest infections other than bronchitis, diagnosis of asthma, pancreatic abnormalities, chronic peptic ulcer, cor pulmonale, and arteriosclerotic aneurysm of the aorta.

The clinical diagnosis of emphysema correlated well with the severity of emphysema at necropsy and, in the absence of other severe disease, was usually correctly made. The routine radiographic diagnosis was correct in $71 \%$ of the patients with severe emphysema.

Death certificates underestimated the incidence of severe emphysema at necropsy, but when it was recorded on a death certificate as a cause of death a significant degree of emphysema was present.

A history of chronic bronchitis was present in $85 \%$ of patients with severe emphysema, and in the remaining $15 \%$ hypertrophy of the bronchial mucous glands was present.

A statistically significant association was found between the amount of emphysema and the following: smoking, the diagnosis of asthma, pulmonary infections other than bronchitis, arteriosclerotic aneurysm of the aorta, and cor pulmonale. Patients with severe emphysema were also heavier cigarette smokers.

No statistically significant association could be found between emphysema and chronic peptic ulcer or lesions of the pancreas. The increased incidence of chronic peptic ulcer in the patients with severe emphysema is thought to be due to the fact that the great majority of them were men and they were older than the random necropsy population.

I would like to thank Dr. B. Castleman for advice and encouragement, and Dr. Ronald Sniffen and Dr. G. C. McMillan for help with the manuscript.

The material reported here was collected during the tenure of the Paul Dudley White Fellowship in Cardiology of the Massachusetts Heart Association. Further support was received from the American Thoracic Society and a Dominion Provincial Grant No. 604-7-266 of Canada.

\section{REFERENCES}

Andral (1838). Notes of Professor Andral, in Laennec, R. T. H., translated by John D. Fisher.

Baldwin, E. deF., Cournand, A., and Richards, D. W., Jr. (1949). Medicine (Baltimore), 28, 201.

Bates, D. V. (1958). J. clin. Invest., 37, 591.

Woolf, C. R., and Paul, G. I. (1962). Med. Serv. J. Can., 18, 211. Case Records of the Massachusetts General Hospital (Case 46351) (1960a). New Engl. J. Med., 263, 456. (Case 46441) (1960b). Ibid., 263, 913.

Ciba Guest Symposium (1959). Thorax, 14, 286.

Cohen, A. C., and Jenney, F. S. (1962). Amer. Rev. resp. Dis., 85, 130. Cromie, J. B. (1961). Ibid., 84, 657.

Fletcher, C. M. (1959). Ibid., 80, 483.

Flint, F. J., and Warrack, A. J. N. (1958). Lancet, 2, 178.

Franklin, W., and Lowell, F. C. (1961). Ann. intern. Med., 54, 379

Franklin, W., and Lowell, F. C. (1961). Ann. intern. Med., 54, 379.

Fulton, R. M. (1953). Quart. J. Med., 22, 43.

Gaensler, E. A., and Lindgren, I. (1959). Amer. Rev. resp. Dis., 80, No. 1, Pt 2, p. 185.

Gough, J. (1955). Lancet, 1, 161.

Green, P. T., and Dundee, J. C. (1952). Canad. med. Ass. J., 67, 438.

Heard, B. E. (1958). Thorax, 13, 136.

Heppleston, A. G., and Leopold, J. G. (1961). Amer. J. Med., 31, 279.

Knott, J. M. S., and Christie, R. V. (1951). Lancet, 1, 881.

Laennec, R. T. H. (1838). A Treat ise on the Diseases of the Chest and on Mediate Auscultation, 4th ed. Translated by J. Forbes. Wood, New York.

Latts, E. M., Cummins, J. F., and Zieve, L. (1956). A.M.A. Arch. intern. Med., 97, 576.

Leese, W. L. B. (1956). Lancet, 2, 762.

Leopold, J. G., and Gough, J. (1957). Thorax, 12, 219.

Louis, P. C. A. (1838). Researches on Emphysema of the Lungs. Translated by T. Stewardson, Jr. In Dunglison's American Medical Library, p. 491. Philadelphia.

Lowell, F. C., Franklin, W., Michelson, A. L., and Schiller, I. W. (1956a). New Engl. J. Med., 254, 123.

(1956b). Ann. intern. Med., 45, 268.

McNeil, W. L. (1961). (Massachusetts Registrar of Vital Statistics.) Personal communication.

Monroe, R. T. (1951). Diseases in Old Age, 1st ed. Harvard University Press, Cambridge, Mass.

Oswald, N. C., Harold, J. T., and Martin, W. J. (1953). Lancet, 2, 639. Oswald, N. C., Harold, J. T.955). lbid., 2, 843.

Palmer, K. N. V. (1954). Brit. med. J., 1, 1473.

Plotkin, Z. (1957). Dis. Chest, 31, 195.

Polgar, G., and Denton, R. (1962). Amer. Rev. resp. Dis., 85, 319. Reid, Lynne (1960). Thorax, 15, 132.

Silen, W., Brown, W. H., and Eiseman, B. (1959). A.M.A. Arch. Surg., 78, 897 .

Sweet, H. C., Wyatt, J. P., Fritsch, A. J., and Kinsella, P. W. (1961). Ann. intern. Med., 55, 565.

Waters, A. T. H. (1862). Researches on the Nature, Pathology, and Treatment of Emphysema of the Lungs, and Its Relations with Other Diseases of the Chest. Churchill, London.

Whitfield, A. G. W., Smith, O. E., Richards, D. G. B., Waterhouse, J. A. H., and Arnott, W. M. (1951). Quart J. Med., 20, 247.

Wood, J. A., Fishman, A. P., Reemtsma, K., Barker, H. G., and di, J. A., Fishman, A. (1959). New Engl.J. Med. 260, 95i.

Zasly, L., Baum, G. L., and Rumball, J. M. (1960). Dis. Chest, 37, 400. 